\title{
A case-based systematic review on the SARS-COVID-2-associated cerebrovascular diseases and the possible virus routes of entry
}

\author{
Ali Lashkari ${ }^{1} \cdot$ Reza Ranjbar $^{2}$
}

Received: 28 May 2021 / Revised: 13 August 2021 / Accepted: 20 August 2021 / Published online: 21 September 2021

(c) Journal of NeuroVirology, Inc. 2021

\begin{abstract}
Severe acute respiratory syndrome coronavirus 2 (SARS-CoV-2) sparked a global pandemic that continues to affect various facets of human existence. Many sources reported virus-induced acute cerebrovascular disorders. Systematically, this paper reviews the case studies of COVID-19-related acute cerebrovascular diseases such as ischaemic stroke, intracerebral hemorrhage, and cerebral sinus thrombosis. We also spoke about how SARS-CoV-2 can infect the brain and trigger the aforementioned disorders. We stated that SARS-CoV-2 neuroinvasion and BBB dysfunction could cause the observed disorders; however, further research is required to specify the mechanisms and pathogenesis of the virus.
\end{abstract}

Keywords COVID-19 · Intracranial hemorrhage · Cerebrovascular · Ischemic stroke $\cdot$ Cerebral venous sinus thrombosis

\section{Introduction}

Coronaviruses (CoVs) are enveloped, single-stranded RNA viruses that belong to the Coronavirinae subfamily of the Coronavirdiae family of the Nidovirales order (Halaji et al. 2020). The nucleocapsid of the virion is made up of genomic RNA and phosphorylated nucleocapsid $(\mathrm{N})$ protein. It is buried between phospholipid bilayers and protected by spike proteins; the membrane (M) protein (a type III transmembrane glycoprotein) and the envelope (E) protein of the virus envelope are found among the spike (S) proteins. This virus is named corona because of its crown-like look $(\mathrm{Li}$ et al. 2020a, b; Mohammadpour et al. 2021). The COVID19 , with more than 127 million cases and 2.7 million deaths, caused a worldwide pandemic. It had many devastating effects on different aspects of human life worldwide (Heiat et al. 2021; Mirzaie et al. 2020).

Although SARS-CoV-2 mainly causes acute respiratory distress syndrome (ARDS), it has also been reported to be a neuroinvasive agent (Achar and Ghosh 2020; Allahyari

Reza Ranjbar

ranjbarre@gmail.com

1 Institute of Biochemistry and Biophysics (IBB), University of Tehran, Tehran, Iran

2 Molecular Biology Research Center, Systems Biology and Poisonings Institute, Baqiyatallah University of Medical Sciences, Tehran, Iran et al. 2021; Mirzaei et al. 2020). In a retrospective sample of COVID-19 patients from Wuhan, China, neurological signs were seen in $36.4 \%$ of overall patients and $45.5 \%$ of patients with severe infections (Mao et al. 2020). Cerebrovascular disease is defined as a condition in which a part of the brain is damaged briefly or fatally due to ischemia or bleeding. Acute cerebrovascular disorders are among the most frequent comorbidities in COVID-19 patients (Aghamollaei et al. 2021; Mirzaei et al. 2020; Wang et al. 2020).

In this systematic review, we focused on the reported cases of acute cerebrovascular disorders diagnosed with COVID-19. We also discussed the possible mechanisms of entry of the virus regarding cerebrovascular disorders.

\section{Methods}

A systematic literature search including articles published from January 1, 2020, to April 15, 2021, was performed on PubMed using different combinations of the following search terms: "COVID-19," "Coronavirus," "Sars-Cov-2," and "ischemic stroke," "cerebrovascular," "intracranial hemorrhage," "intracranial bleeding," "subarachnoid hemorrhage," "intracerebral hemorrhage," and "cerebral venous sinus thrombosis." The PubMed was searched as follow:

"( (( (()(COVID-19 Coronavirus Sars-Cov-2) AND (ischemic stroke)) OR ((COVID-19 Coronavirus SarsCov-2) AND (cerebrovascular))) OR ((COVID-19 
Coronavirus Sars-Cov-2) AND (intracranial hemorrhage))) OR ((COVID-19 Coronavirus Sars-Cov-2) AND (intracranial bleeding $))$ ) OR ((COVID-19 Coronavirus Sars-Cov-2) AND (subarachnoid hemorrhage))) OR ((COVID-19 Coronavirus Sars-Cov-2) AND (intracerebral hemorrhage))) OR ((COVID-19 Coronavirus Sars-Cov-2) AND (cerebral venous sinus thrombosis))."

Only articles published in English were reviewed. The articles reporting case data on stroke mechanism and etiology, sex, age, past cardiovascular risk factors, COVID symptoms, admission National Institutes of Health Stroke (NIHSS) score, D-dimer levels, and acute stroke treatment were selected for the review and those without the clinical description of the cases were excluded. Afterwards, the collected articles were reviewed, and relevant articles were used for data extraction. Two authors independently searched and reviewed the titles, abstracts, and keywords of collected papers and resolved the issue in case of uncertainty and disagreement before continuing to the next step. All the procedures of literature search, article selection, and data synthesis were performed according to the PRISMA checklist 2009, which is a known and standard protocol for reporting systematic reviews (Liberati et al. 2009). IBM SPSS Statistics for Windows version 10.0 (IBM, Armonk, NY, USA) were used for statistical analysis of the data. The results are reported as the mean $\pm \mathrm{SD}$.

\section{Results}

The study selection pathway is shown in Fig. 1. Five hundred eighty-four articles were excluded from a total of 733 articles published from January 1, 2020, to April 15, 2020, because they either were not in English or did not report a clinical case. Due to the lack of relevant titles or abstracts, 52 articles were excluded from the remaining 149 . From the remaining articles, 25 were excluded because although they were related to COVID19 and cerebrovascular diseases, case descriptions of ischemic stroke (IS), intracranial bleeding, or CVST, and individual clinical data were not reported. The remaining 71 articles (127 patients) that satisfied the criteria mentioned above were included in this review. In this review, 80 cases of patients developed IS during COVID-19 infection (Aasfara et al. 2021; Abdulkadir et al. 2020; Agarwal et al. 2020; Al-Mufti et al. 2021; Al Saiegh et al. 2020; Appavu et al. 2021; Ashraf and Sajed 2020; Avula et al. 2020; Bessa et al. 2020; Bigliardi et al. 2020; Burkert and Patil 2020; Co et al. 2020; Dakay et al. 2020a, b; de Almeida Lima et al. 2020; de Lorenzo Alvarez et al. 2021; Deliwala et al. 2020; Dumitrascu et al. 2020; Efendizade et al. 2020; El Nahas et al. 2020; Elshereye and Erdinc 2020; Eskandarani
Fig. 1 Study selection pathway

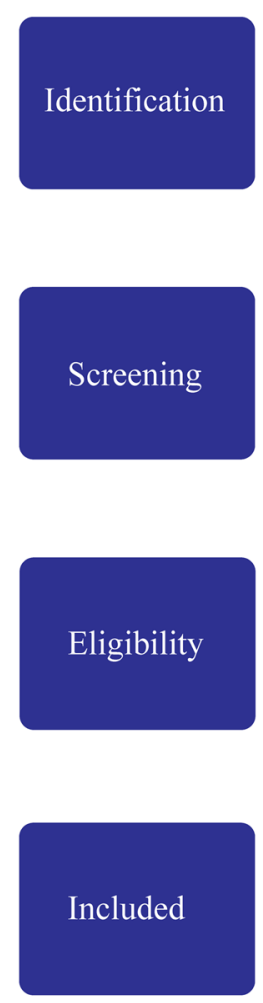

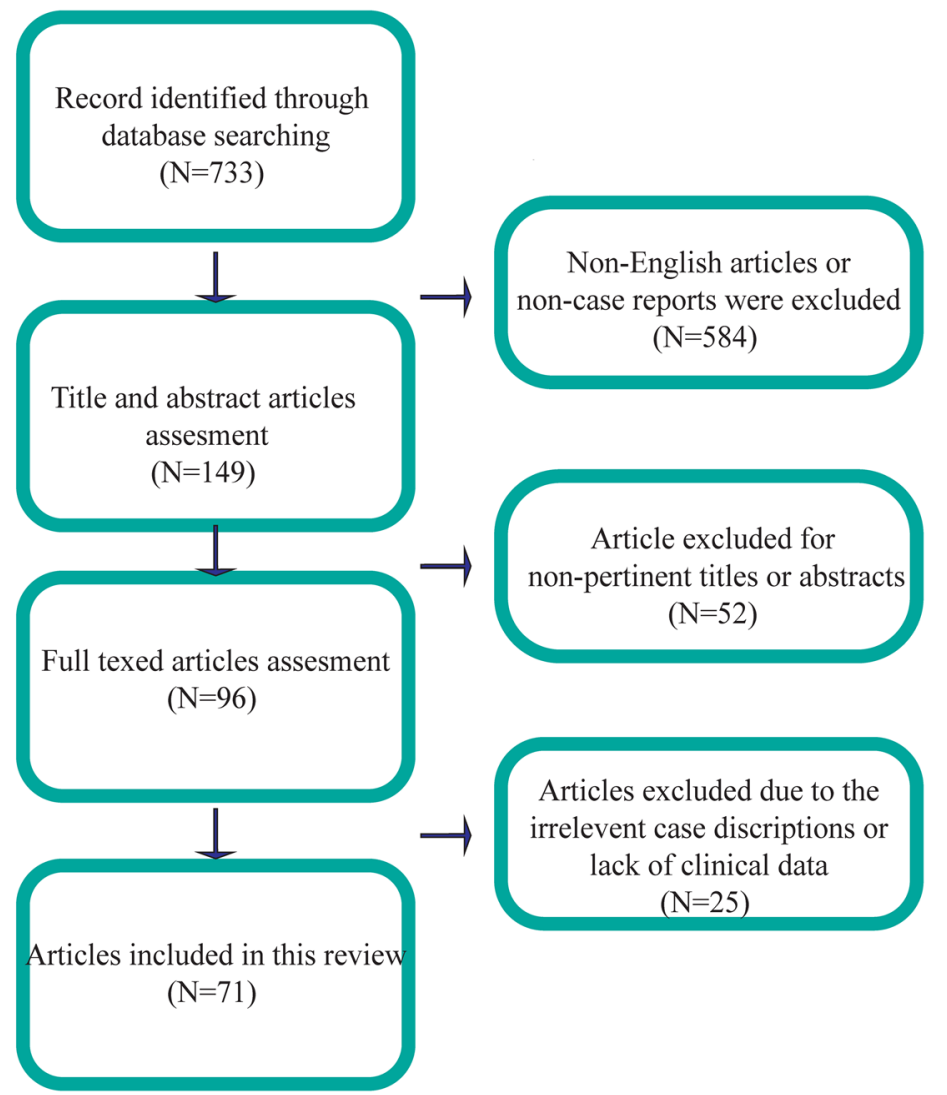


et al. 2021; Fu et al. 2021; Garg et al., 2020; Gemcioglu et al. 2020; Goette et al. 2020; Goldberg et al. 2020; Guillan et al. 2020; Iqbal et al. 2021; Kwon et al. 2020; Mahboob et al. 2020; Mansour et al. 2020; Mirzaee et al. 2020; Morassi et al. 2020; Mowla et al. 2020; Patel et al. 2020a, b; Patel et al. 2020a, b; Prasad et al. 2021; Priftis et al. 2020; Rajdev et al. 2020; Rascón-Ramírez et al. 2020; Roy et al. 2021; Valderrama et al. 2020; Viguier et al. 2020; Zhai et al. 2020), 32 cases developed intracranial hemorrhage (Ahmad et al. 2021; Al-Mufti et al. 2021; Al Saiegh et al. 2020; Carroll and Lewis 2021; Cezar-Junior et al. 2020; Dakay et al. 2020a, b; Dakay et al. 2020a, b; Fayed et al. 2020; Flores et al. 2020; Ghani et al. 2020; Haider et al. 2020; Heman-Ackah et al. 2020; Krzystanek et al. 2021; Morassi et al. 2020; Motoie et al. 2020; Mousa-Ibrahim et al. 2021; Rajdev et al. 2020; Savić et al. 2020; Thibodeau et al. 2021; Thu et al. 2020; Zahid et al. 2020), and 15 cases CVST (Bolaji et al. 2020; Cardoso et al. 2021; Dakay et al. 2021; Guendouz et al. 2021; Haroon et al. 2020; Kaur et al. 2021; Khazaei et al. 2021; Nwajei et al. 2020).

\section{Types of studies}

Only case reports and case series were included.

\section{Ischemic stroke}

Eighty patients with IS were reported (Table 1), among which $65 \%$ were male. The average age was 59 years old. Eighty percent of patients (64 patients) reported having a history of vascular risk factors. The most significant past medical histories were hypertension (43 patients, 53.09\%) and diabetes mellitus (22 patients, 27.5\%). Ten patients $(12.5 \%)$ had a previous stroke or transient ischemic attack (TIA). The symptoms of COVID-19 were reported in 54 patients (67.5\%); 41 (51.25\%) had cough, 39(48.75\%) had fever, and 24 (30\%) had dyspnea. The NIHSS score was reported in 44 cases (55\%), with an average of 11.53 and a range of $2 \pm 36$. In 37 patients $(46.25 \%)$, D-dimer has been reported with a mean value of 13,277 [ $\pm 57,927] \mathrm{ng} /$ $\mathrm{mL}$ (range 300-350,000). Ferritin level was reported in 26 patients $(32.5 \%)$ with a mean value of $1235 \pm 2251 \mathrm{ng} /$ $\mathrm{mL}$. In 35 patients $(43.75 \%)$, the WBC count was reported (mean: $9320 \pm 3750 / \mathrm{mm}^{3}$; range: $200-18,900$ ). Platelet count reported in 38 cases (47.5\%; mean: $244,29 \pm 115,62$ / mm3; range: 9000- 569,000). The level of C-reactive protein (CRP) has been reported in $58(72.5 \%)$ patients (mean: $246.9 \pm 459.00 \mathrm{mg} / \mathrm{L}$; range: $0.1-2200$ ). The shortterm outcomes have been reported in 64 patients $(80 \%)$; the results showed that 28 patients $(35 \%)$ survived ad discharged from the hospital, ten patients (12.5\%) were
Table 1 Characteristics of ischemic stroke-associated COVID-19 patients

\begin{tabular}{ll}
\hline Patient characteristics & Values \\
& No.-\%; mean $[ \pm$ SD $] ;$ (range) \\
\hline Age (years) & $59.21 \pm[16.80] ;(8-88)$ \\
Sex & $35 \%$ female \\
Cardiovascular risk factors & $80 \%$ \\
Arterial hypertension & $53.75 \%$ \\
Diabetes mellitus & $27.50 \%$ \\
Hyperlipidemia & $12.50 \%$ \\
Atrial fibrillation & $5 \%$ \\
Coronary artery disease & $17.50 \%$ \\
Smoking & $10 \%$ \\
Obesity & $6.25 \%$ \\
Previous stroke or TIA & $12.50 \%$ \\
NIHSS & $11.52 \pm[6.29] ;(2-36)$ \\
COVID-19 symptoms & $67.50 \%$ \\
Fever & $48.75 \%$ \\
Cough & $51.25 \%$ \\
Dyspnea & $30 \%$ \\
Vomiting and diarrhea & $13.75 \%$ \\
Body aches or myalgias & $12.50 \%$ \\
D-Dimer (ng/mL) & $13,276.69 \pm[57,926.9] ;(300-350,000)$ \\
Ferritin (ng/mL) & $1234.64 \pm[2251.2] ;(0.113-10,576)$ \\
WBC counts $\left(10^{3} / \mu L\right)$ & $9.32 \pm[3.8] ;(0.2-18.89)$ \\
Platelet count $\left(10^{3} / \mu L\right)$ & $244.29 \pm[115.6] ;(9-569)$ \\
CRP (mg/L) & $246.90 \pm[459] ;(0.1-2200)$ \\
Short-term outcome & $80 \%$ \\
Survival & $35 \%$ \\
critically ill & $12.50 \%$ \\
Death & $31.25 \%$ \\
\hline & \\
& \\
&
\end{tabular}

critically ill and stayed in the intensive unit care ICU, and 25 patients $(3125 \%)$ were expired.

\section{Intracerebral hemorrhage}

Thirty-five cases of acute Intracerebral hemorrhage associated with COVID-19 have been reported (Table 2). Among these cases, 20 patients $(62.5 \%)$ had an intracerebral hemorrhage (ICH), ten patients $(11.43 \%)$ had subarachnoid hemorrhage (SAH), and two patients $(6.27 \%)$ had both SAH and ICH. Eighteen patients $(56.52 \%)$ were male, and 14 patients $(43.75 \%)$ were female. The average age of the patients was $55.56 \pm 16.32$ years. Twenty-six patients $(81.25 \%)$ had a history of cardiovascular risk factors. The most common risk factors were arterial hypertension (16 patients, $50 \%$ ), diabetes mellitus (6 patients, $18.75 \%$ ), and obesity (6 patients, $18.75 \%$ ). 
Table 2 Characteristics of intracranial hemorrhage-associated COVID19 patients

\begin{tabular}{ll}
\hline Patient characteristics & Values \\
& No.- $\%$; mean $[ \pm$ SD $] ;$ (range) \\
\hline Age (years) & $55.56 \pm[16.3] ;(13-82)$ \\
Sex & $56.25 \%$ female \\
Cardiovascular risk factors & $81.25 \%$ \\
Arterial hypertension & $50 \%$ \\
Diabetes mellitus & $18.75 \%$ \\
Hyperlipidemia & $9.38 \%$ \\
Atrial fibrillation & $3.13 \%$ \\
Coronary artery disease & $6.25 \%$ \\
Smoking & $3.13 \%$ \\
Obesity & $18.75 \%$ \\
Type of intracranial bleeding & $100 \%$ \\
ICH & $62.50 \%$ \\
SAH & $31.25 \%$ \\
SAH+ICH & $6.25 \%$ \\
COVID-19 symptoms & $81.25 \%$ \\
Fever & $50 \%$ \\
Cough & $46.88 \%$ \\
Dyspnea & $50 \%$ \\
Vomiting and diarrhea & $6.25 \%$ \\
Body aches or myalgias & $18.75 \%$ \\
D-Dimer (ng/mL) & $4263.31 \pm[5598.3] ;(1040-19,720)$ \\
Ferritin (ng/mL) & $3504 \pm[3088.2] ;(800-8530)$ \\
WBC counts $\left(10^{3} / \mu L\right)$ & $14.91 \pm[10.6] ;(5.7-43.1)$ \\
Platelet count $\left(10^{3} / \mu L\right)$ & $242.67 \pm[133.8] ;(131-539)$ \\
CRP (mg/L) & $204.83 \pm[262.1] ;(4-1070.8)$ \\
Short-term outcome & $87.50 \%$ \\
Survival & $28.13 \%$ \\
Critically ill & $6.25 \%$ \\
Death & $53.13 \%$ \\
\hline
\end{tabular}

ICH neurology is characterized by changes consistent with consciousness with focal symptoms such as motor or sensory deficits, aphasia, and dysarthria in most patients.

The COVID-19 symptoms have been reported in 26 patients (81.25\%); fever 16 (50\%), dyspnea $16(50 \%)$, and cough $15(46.88 \%$ ) were the most common symptoms.

The D-dimer level was reported in 17 patients $(53.13 \%)$ with an average of $4263.31 \pm 5598.25$ and a range of 1040-19,720, whereas the level the ferritin level was reported only in 5 patients $(15.63 \%)$ with an average of $3504 \pm 3088 \mathrm{ng} / \mathrm{mL}$. WBC count was reported in 11 patients $(34.4 \%)$ with an average of $14,910 \pm 10,610 / \mathrm{mm}^{3}$; a range of $5700-43,100$. In addition, CRP levels were reported in 15 patients (46.88\%) with an average of $204.83 \pm 133.82 \mathrm{mg} / \mathrm{L}$ and a range of 4-1070.8. The platelet count was reported in 9 patients (28.13\%) with an average of $242,670 \pm 133,820 /$ $\mathrm{mm}^{3}$, and a platelet range of $131,000-539,000$.
Table 3 Characteristics of cerebral venous sinus thrombosis-associated COVID-19 patients

\begin{tabular}{ll}
\hline Patient characteristics & Values \\
& No.-\%; mean $[ \pm$ SD]; (range) \\
\hline Age (years) & $45.33 \pm[19.4] ;(17-79)$ \\
Sex & $40 \%$ female \\
Cardiovascular risk factors & $53.33 \%$ \\
None & $20 \%$ \\
Arterial hypertension & $13.33 \%$ \\
Diabetes mellitus & $13.33 \%$ \\
Smoking & $0 \%$ \\
Obesity & $20 \%$ \\
COVID-19 symptoms & $60 \%$ \\
Fever & $46.67 \%$ \\
Cough & $33.33 \%$ \\
Dyspnea & $20 \%$ \\
Vomiting and diarrhea & $20 \%$ \\
Body aches or myalgias & $0 \%$ \\
Asymptomatic & $6.67 \%$ \\
Sinus and vein involvement & $86.67 \%$ \\
Transverse sinus & $66.67 \%$ \\
Straight sinus & $20 \%$ \\
Sigmoid sinus & $33.33 \%$ \\
Vein of Galen & $13.33 \%$ \\
Superior sagittal sinus & $60 \%$ \\
Inferior sagittal sinus & $6.67 \%$ \\
Internal cerebral veins & $6.67 \%$ \\
Hemorrhagic transformation & $33.33 \%$ \\
D-Dimer (ng/mL) & $1091.77 \pm[1558.4] ;(2.41-4770)$ \\
Ferritin (ng/mL) & $420.25 \pm[356.3] ;(24-812)$ \\
WBC counts $\left(10^{3} / \mu \mathrm{L}\right)$ & $8.36 \pm[4] ;(4-15.7)$ \\
Platelet count $(103 / \mu L)$ & $233.43 \pm[106.1] ;(113-425)$ \\
CRP (mg/L) & $111.86 \pm[177.3] ;(.29-600)$ \\
Short-term outcome & $100 \%$ \\
Survival & $93.33 \%$ \\
Critically ill & $6.67 \%$ \\
Death & $6.67 \%$ \\
\hline
\end{tabular}

The result of the short-term outcome of the 28 patients $(87.5 \%)$ is as follows; 9 patients survived $(28.13 \%)$, two remain critically ill (6.25\%), and 19 patients were expired $(53.13 \%)$.

\section{Cerebral venous sinus thrombosis}

Sixteen cases of CVST associated with COVID-19 were reported, 9 of them (60\%) were males, $40 \%$ were female, the average age was $45.33 \pm 19.40$, and case age range was $17-79$ years (Table 3$)(28,39,122-130)$.

The cardiovascular risk factors have been reported for 8 cases $(53.33 \%)$. Obesity in three patients $(20 \%)$ was the 
most common risk factor. The COVID-19 symptoms were reported for 9 patients (60\%). The main symptoms were fever 7 (46.67\%), cough 5 (33.33\%), and dyspnea 3 (20\%). In addition, one patient reported being asymptomatic. Headache and change in mental states with focal signs such as motor and sensory deficits, aphasia, impaired perception, and epilepsy were neurological manifestations of CVST in patients with COVID-19. Sinus and vein involvement was reported in 13 patients $(86.67 \%)$. Transverse sinus with 10 (66.67\%) reported cases and superior sagittal sinus with 9 reported cases $(60 \%)$ were the most common sinus involvements. Besides, venous infarction with hemorrhagic transformation was reported in 5 patients (33.33\%). The D-dimer level was reported in 9 cases $(60 \%)$ with an average of $1091.8 \pm 1558 \mathrm{ng} / \mathrm{mL}$ and a range of $2.41-4770 \mathrm{ng} / \mathrm{mL}$. The Ferritin level was detailed in 4 patients $(26.67 \%)$ with the mean value of $420.25 \pm 356 \mathrm{ng} / \mathrm{mL}$. The WBC count level was reported in 8 patients (53.33\%) with an average of $8360 \pm 4020 / \mathrm{mm}^{3}$; also, the platelet count level was reported in 8 patients $(53.33 \%$ ) with an average of $233,430 \pm 106,130$ / $\mathrm{mm}^{3}$. The CPR level was reported in11 patients (73.33\%) with an average of $111.86 \pm 177 \mathrm{mg} / \mathrm{L}$. The short-term outcome was available for all patients; 13 patients (93.33\%) survived, one patient $(6.67 \%)$ was critically ill, and one patient $(6.67 \%)$ died.

\section{The possible routes of entry}

The entry route of a virus into the brain directly affects pathogenic pathways that trigger neurological symptoms. The entry route of SARS-CoV-2 into the brain is still unknown. However, based on the neurological symptoms of COVID19, two potential routes may be proposed: transneuronal spread via the olfactory nerves and hematogenous spread after crossing the blood-brain barrier (BBB) (Achar and Ghosh 2020; Allahyari et al. 2021; Kumar et al. 2020).

The former can result in loss of smell and taste. In this case, SARS-CoV-2, which is found in the nasal endothelium, can attach to motor proteins and move with it along sensory and olfactory nerves to the brain (Briguglio et al. 2020; Eliezer et al. 2020). A retrospective analysis of 114 COVID19 patients from the Nord Franche-Comté hospital declared that $47 \%$ of them had anosmia (Klopfenstein et al. 2020). The frequency of olfactory disorder ranges across nations, which differs from 33.9 to $68 \%$ (Meng et al. 2020). Brann et al. (2020) have discovered ACE2 expression in human olfactory epithelium sustentacular cells, horizontal basal cells, and Bowman's gland, which explains the anosmia associated with COVID-19 and can also be proof for the transneuronal spread via the olfactory nerves mechanism. On the other hand, cerebrovascular symptoms, such as stroke, appear when SARS-CoV-2 have been transmitted through the vascular system after respiratory tract inflammation
(Baig 2020). In that case, SARS-CoV-2 can then circulate across the cerebral vascular system. However, to migrate to the brain, it needs to permeate into the blood-brain barrier (BBB) (Achar and Ghosh 2020; Hosseini et al. 2021). The $\mathrm{BBB}$ is a semi-permeable membrane that separates blood vessels from brain parenchyma and vascularizes the CNS. It specifically regulates which molecules are allowed to move through (Abbott 2002). Transcellular migration, paracellular migration, and the "Trojan horse" technique are the three major pathways through which a virus can cross the BBB (Fig. 2) (Dahm et al. 2016). Viruses infect host endothelial cells to cross the BBB through transcellular migration. Viruses penetrate close junctions created by BBB endothelial cells during paracellular migration (Robinson and Busl 2020). A virus is engulfed by phagocytic host cells such as neutrophils and macrophages during the Trojan horse technique. SARS-CoV-2 can use a single or a mixture of these mechanisms (Dahm et al. 2016). SARS-CoV-2 can use either ACE2 and associated viral entry receptors in vascular endothelium, blood cells such as dendritic cells and macrophages, or cytokine storm on the blood-brain barrier to cross the BBB (Kumar et al. 2020).

\section{ACE2 receptor-based invasion}

SARS-CoV-2 binds to a human cell surface receptor named angiotensin-converting enzyme 2 (ACE2) through the receptor-binding domain (RBD) of its spike (S) protein. Moreover, it appears that cleavage of the viral $\mathrm{S}$ protein by proteases such as transmembrane protease serine 2 (TMPRSS2) or cathepsin L (CTSL) is necessary to penetrate host cell membrane fusion and activate virus infectivity. ACE2 has been shown to co-express with TMPRSS2/ CTSL in specific cell subsets through human tissue groups, including the brain (Lan et al. 2020; Zhu et al. 2013). If SARS-CoV-2 enters the cell, it starts replication in the cytoplasm. The genome is first transcribed by an RNAdependent RNA polymerase unique to SARS-CoV-2. The resulting antigenome template is then transcribed to generate positive-strand RNA and mRNAs, which are then capped and polyadenylated to create peptides. Viral RNA is dispersed to adjacent cells via viral exocytosis. Hence, the expression of ACE2 and associated proteases such as TMPRSS2, CTSL, and FURIN on the host cell is necessary for the entry of SARS-CoV-2 (Shang et al. 2020). The broad distribution of ACE2 protein in neurons and cells near the lumen in human brain organoids has been observed previously. SARS-CoV-2 can invade brain organoids and can be prevented by utilizing ACE2 specific antibodies or by applying cerebrospinal fluid to a patient with COVID19. Therefore, ACE2 is needed for brain organoid infection (Pavillet and Selvakumar 2020; Song et al. 2020). The presence of ACE2 and related proteases in the vascular 




Fig. 2 (SARS-CoV-2) hematogenic pathway to the central nervous system (CNS). On this route, SARS-CoV-2, by three strategies, including transcellular

endothelium as well as concrete signs of SARS-CoV-2 invasion suggests that the hematogenous passage to the brain seems plausible (Sungnak et al. 2020; Ziegler et al. 2020).

\section{Cytokine storm}

Cytokines are glycosylated polypeptides that play an immunomodulatory role in immune responses. In the late stages of the infection, neurological effects can also occur due to the cytokine storm's indirect chemical impact (Allan and Rothwell 2001; Mehta et al. 2020). Pro-inflammatory cytokines promote activation of the immune cells at the site of infection, which brings leukocytes to the infection, helping the immune system respond by producing higher levels of inflammation (Zhang and An 2007). Nevertheless, infection by SARS-2 frequently causes overexpression of cytokines called a "cytokine storm," which results in the overactivation of the inflammatory response (Wong et al. 2004). TNF- $\alpha$, IFN- $\gamma$, IL-2, IL-4, IL-6, IL-8, and IL-10 levels, for example, were shown to be higher in COVID-19 patients. In addition, patients with severe COVID-19 have been shown to have elevated levels of pro-inflammatory cytokines compared to the patients with non-severe COVID-19 (Han et al. 2020; Qin et al. 2020). This "cytokine storm" may also cause the BBB to become permeable, making viral entry via the hematogenous route easier. For instance, IL- 6 has been shown to play a major role in the immune dysregulation of COVID-19 patients (Mandel et al. 2020). Besides, in vitro study of IL-6 also showed the reduction of interendothelial adherens and tight junction proteins, resulting in increased paracellular permeability in human brain microvascular endothelial cells (Rochfort et al. 2014). On the other hand, anti-IL-6 neutralizing antibodies have been found to decrease BBB permeability caused by ischemia, indicating that IL-6 may play a role in BBB malfunction in disorders including ischaemic injury in the ovine fetus (Zhang et al. 2015). In addition to IL-6, patients with COVID-19-associated neurological signs were shown to have higher amounts of IL-8 in their cerebrospinal fluid (Benameur et al. 2020). Endothelial cells and microglia in the CNS produce IL-8, which plays an integral role in leukocyte extravasation into the BBB (Ehrlich et al. 1998). Thus, the sudden production of pro-inflammatory cytokines during the cytokine storm raises the level of immune responses. However, a cytokine storm can stimulate the inflammatory response and disrupt the BBB (Daneman and Prat 2015). As a result, the function of endothelial cells, pericytes, and astrocytes to inhibit immune cells from infiltrating the brain is compromised. According to reports, the resultant neuroinflammatory reaction may cause severe brain harm. It may also trigger clotting of the cerebral vasculature, which may cause stroke-like symptoms (Mizuguchi et al. 2007; Varatharaj and Galea 2017).

\section{Discussion}

Stroke can result from acute and chronic infection (Grau et al. 2010). Acute ischemic stroke is a sudden lack of blood supply to a region of the brain, culminating in a loss of neurologic functionality. It is triggered by thrombosis 
or embolism, which obstructs a cerebral artery that supplies a particular region of the brain (González et al. 2011). In accordance with our study, one of the most frequent acute cerebrovascular diseases seen in COVID-19 populations is stroke. Ischemic stroke occurs at a rate of 5.7\% (Li et al. 2020a, b). Li et al. (2020b) reported $4.6 \%$ of 219 COVID-19 patients with acute ischemic stroke were more than one-third of hospitalized patients. Hassett and Frontera (2021) also reported a stroke rate of 1-2\% in hospitalized COVID19 patients of 17 healthcare networks from four countries. Based on the initial reports from Wuhan, patients with COVID-19-associated stroke tend to be older, have a severe infection, and have cardiovascular risk factors, like diabetes, hypertension, and stroke history ( $\mathrm{Li}$ et al. 2020a, b). Other available data, on the other hand, also confirmed the prevalence of stroke in younger patients $(>50 \mathrm{y} / \mathrm{o})$ with no vascular risk factors (Fifi and Mocco 2020).

The intracerebral hemorrhage caused by COVID-19 infection is less frequent than ischemic stroke, with confirmed incidence rates ranging between 0.2 and $0.4 \%$ (Hassett and Frontera 2021). However, the fatal rate for hospitalized patients with COVID-19-associated intracerebral hemorrhage was over 50\% [6]. The ICHs associated with COVID-19 seem to be more intraparenchymal with lobar location and multicompartmental; they also have multiple foci; there are few reported cases of nonaneurysmal subarachnoid hemorrhage (Kirschenbaum et al. 2020).

The development of a blood clot in the dural venous sinuses, which withdraws blood from the brain, is known as cerebral venous sinus thrombosis (CSVT) (Agrawal et al. 2016). CSVT-associated COVID-19 is also less frequent than acute ischemic and hemorrhagic stroke. Also, the patients with CSVT seem to have fewer medical past history; in one study by Tu et al. (2020), almost $60 \%$ of patients had no significant prior medical problems.

\section{Conclusions}

The recent reports of a severe epidemic COVID-19 have demonstrated that COVID-19-associated acute cerebrovascular disorders pose a risk to patients' lives. The most common causes of COVID-19-associated cerebrovascular disorders are acute ischemic stroke, followed by intracerebral hemorrhage, and cerebral sinus thrombosis. Based on the current evidence, a hematogenous route of viral brain entry, which can cross the BBB, and justify cerebrovascular symptoms, is entirely plausible for COVID-19. Also, there are other causes, such as cytokine storm, that can induce neuroinflammation, and result in the COVID-19 neurological symptoms. Thus, identifying COVID-19-associated acute cerebrovascular diseases as a possibly lethal organ failure, as well as its mode of action and entry route, is crucial for early empirical treatment to rescue critically sick COVID19 patients. However, there is little conclusive evidence of SARS-CoV-2 unique neuropathogenic. Further research is required to obtain a better insight into its pathogenesis, laboratory diagnosis, and treatment.

Acknowledgements The authors would like to thank the Clinical Research Development Unit of Baqiyatallah Hospital, Tehran, Iran, for guidance and advice.

Data availability Data will be made available upon request.

\section{Declarations}

Conflict of interest The authors declare no competing interests.

\section{References}

Aasfara J, Jidane S, Laarje A, Yamani KE, Belyamani L, Tijani Y (2021) SARS-CoV-2, recurrent ischemic strokes and carotid macrothrombosis: the other face of the cytokine storm (a case report). Pan Afr Med J 38:34. https://doi.org/10.11604/pamj. 2021.38.34.27645

Abbott NJ (2002) Astrocyte-endothelial interactions and blood-brain barrier permeability. J Anat 200(5):523-534

Abdulkadir T, Ünlübaş Y, Alemdar M, Akyüz E (2020) Coexistence of COVID-19 and acute ischemic stroke report of four cases. J Clin Neurosci 77:227-229

Achar A, Ghosh C (2020) COVID-19-associated neurological disorders: the potential route of CNS invasion and blood-brain relevance. Cells 9(11):2360

Agarwal A, Pinho M, Raj K, Yu FF, Bathla G, Achilleos M, Maldjian J (2020) Neurological emergencies associated with COVID-19: stroke and beyond. Emerg Radiol 27(6):747-754. https://doi.org/ 10.1007/s10140-020-01837-7

Aghamollaei H, Sarvestani R, Bakherad H, Zare H, Guest PC, Ranjbar R, Sahebkar A (2021) Emerging technologies for the treatment of COVID-19. Clinical, Biological and Molecular Aspects of COVID-19, 81-96

Agrawal K, Burger K, Rothrock JF (2016) Cerebral sinus thrombosis. Headache: The Journal of Head and Face Pain, 56(8)1380-1389

Ahmad H, Shubair SM, Kruer J, Hatoum CA (2021) Acute lowerextremity ischemia in a patient with COVID-19. Am J Case Rep 22:e928471. https://doi.org/10.12659/ajcr.928471

Al-Mufti F, Becker C, Kamal H, Alshammari H, Dodson V, Nuoman R, Gandhi CD (2021) Acute cerebrovascular disorders and vasculopathies associated with significant mortality in SARS-CoV-2 patients admitted to the intensive care unit in the New York Epicenter. J Stroke Cerebrovasc Dis 30(2):105429. https://doi.org/ 10.1016/j.jstrokecerebrovasdis.2020.105429

Al Saiegh F, Ghosh R, Leibold A, Avery MB, Schmidt RF, Theofanis T, Gooch MR (2020) Status of SARS-CoV-2 in cerebrospinal fluid of patients with COVID-19 and stroke. J Neurol Neurosurg Psychiatry 91(8):846-848. https://doi.org/10.1136/ jnnp-2020-323522

Allahyari F, Hosseinzadeh R, Nejad JH, Heiat M, Ranjbar R (2021) A case report of simultaneous autoimmune and COVID-19 encephalitis. J Neurovirol 1-3

Allan SM, Rothwell NJ (2001) Cytokines and acute neurodegeneration. Nat Rev Neurosci 2(10):734-744 
Appavu B, Deng D, Dowling MM, Garg S, Mangum T, Boerwinkle V, Abruzzo T (2021) Arteritis and large vessel occlusive strokes in children after COVID-19 infection. Pediatrics 147(3). https:// doi.org/10.1542/peds.2020-023440

Ashraf M, Sajed S (2020) Acute stroke in a young patient with coronavirus disease 2019 in the presence of patent foramen ovale. Cureus 12(9):e10233. https://doi.org/10.7759/cureus.10233

Avula A, Nalleballe K, Narula N, Sapozhnikov S, Dandu V, Toom S, Elsayegh D (2020) COVID-19 presenting as stroke. Brain Behav Immun 87:115-119. https://doi.org/10.1016/j.bbi.2020.04.077

Baig AM (2020) Neurological manifestations in COVID-19 caused by SARS-CoV-2. CNS Neurosci Ther 26(5):499

Benameur K, Agarwal A, Auld SC, Butters MP, Webster AS, Ozturk T, Schinazi RF (2020) Encephalopathy and encephalitis associated with cerebrospinal fluid cytokine alterations and coronavirus disease, Atlanta, Georgia, USA, 2020. Emerg Infect Dis 26(9):2016

Bessa PB, Brito AKB, Pereira FR, Silva SQE, Almeida TVR, Almeida AP (2020) Ischemic stroke related to HIV and SARS-COV-2 coinfection: a case report. Rev Soc Bras Med Trop 53:e20200692. https://doi.org/10.1590/0037-8682-0692-2020

Bigliardi G, Ciolli L, Giovannini G, Vandelli L, Dell’Acqua ML, Borzì GM, Meletti S (2020) Middle cerebral artery ischemic stroke and COVID-19: a case report. J Neurovirol 26(6):967-969. https:// doi.org/10.1007/s13365-020-00898-1

Bolaji P, Kukoyi B, Ahmad N, Wharton C (2020) Extensive cerebral venous sinus thrombosis: a potential complication in a patient with COVID-19 disease. BMJ Case Rep 13(8). https://doi.org/ 10.1136/bcr-2020-236820

Brann DH, Tsukahara T, Weinreb C, Lipovsek M, Van den Berge K, Gong B, Fletcher RB (2020) Non-neuronal expression of SARSCoV-2 entry genes in the olfactory system suggests mechanisms underlying COVID-19-associated anosmia. Sci Adv 6(31) eabc5801

Briguglio M, Bona A, Porta M, Dell'Osso B, Pregliasco FE, Banfi G (2020) Disentangling the hypothesis of host dysosmia and SARS-CoV-2: the bait symptom that hides neglected neurophysiological routes. Front Physiol 11:671

Burkert J, Patil S (2020) Acute cerebrovascular event in a COVID19 positive patient immediately after commencing non-invasive ventilation. BMJ Case Rep 13(9). https://doi.org/10.1136/ bcr-2020-237737

Cardoso ER, Bains SS, Robison B, Farkas J (2021) Superficial cerebral venous thrombosis and intracerebral hematoma in a 48-year-old man with SARS-CoV-2 infection: a case report. Am J Case Rep 22:e927011. https://doi.org/10.12659/ajcr.927011

Carroll E, Lewis A (2021) Catastrophic intracranial hemorrhage in two critically ill patients with COVID-19. Neurocrit Care 34(1):354 358. https://doi.org/10.1007/s12028-020-00993-5

Cezar-Junior AB, Faquini IV, Silva JLJ, de Carvalho Junior EV, Lemos L, Freire Filho JBM, Azevedo-Filho HRC (2020) Subarachnoid hemorrhage and COVID-19: association or coincidence? Medicine (baltimore) 99(51):e23862. https://doi.org/10.1097/md. 0000000000023862

Co COC, Yu JRT, Laxamana LC, David-Ona DIA (2020) Intravenous thrombolysis for stroke in a COVID-19 positive filipino patient, a case report. J Clin Neurosci 77:234-236. https://doi.org/10. 1016/j.jocn.2020.05.006

Dahm T, Rudolph H, Schwerk C, Schroten H, Tenenbaum T (2016) Neuroinvasion and inflammation in viral central nervous system infections. Mediators of inflammation, 2016

Dakay K, Cooper J, Bloomfield J, Overby P, Mayer SA, Nuoman R, Al-Mufti F (2021) Cerebral venous sinus thrombosis in COVID-19 infection: a case series and review of the literature. J Stroke Cerebrovasc Dis 30(1):105434. https://doi.org/ 10.1016/j.jstrokecerebrovasdis.2020.105434
Dakay K, Kaur G, Gulko E, Santarelli J, Bowers C, Mayer SA, Al-Mufti F (2020a) Reversible cerebral vasoconstriction syndrome and dissection in the setting of COVID-19 infection. J Stroke Cerebrovasc Dis 29(9):105011. https://doi.org/10.1016/j. jstrokecerebrovasdis.2020.105011

Dakay K, Kaur G, Mayer SA, Santarelli J, Gandhi C, Al-Mufti F (2020b) Cerebral herniation secondary to stroke-associated hemorrhagic transformation, fulminant cerebral edema in setting of COVID-19 associated ARDS and active malignancy. J Stroke Cerebrovasc Dis 29(12):105397. https://doi.org/10. 1016/j.jstrokecerebrovasdis.2020.105397

Daneman R, Prat A (2015) The blood-brain barrier. Cold Spring Harbor perspectives in biology, 7(1)a020412

de Almeida Lima AN, Pessoa SLM, Franco Costa Lima C, Picasso de Araújo Coimbra P, Bezerra Holanda JL (2020) Images in vascular medicine: acute peripheral artery occlusion and ischemic stroke in a patient with COVID-19. Vasc Med 25(5):482-483. https://doi.org/10.1177/1358863x20945020

de Lorenzo Alvarez A, Revilla Á, Corbalán T, Villar A, Espinel L, Martins J, Cubas A (2021) Ischemic stroke and purpuric dermatitis as COVID-19-related complications in a peritoneal dialysis patient. CEN Case Rep 10(2):250-254. https://doi.org/10.1007/ s13730-020-00553-y

Deliwala S, Abdulhamid S, Abusalih MF, Al-Qasmi MM, Bachuwa G (2020) Encephalopathy as the sentinel sign of a cortical stroke in a patient infected with coronavirus disease-19 (COVID-19). Cureus 12(5):e8121. https://doi.org/10.7759/cureus.8121

Dumitrascu OM, Volod O, Bose S, Wang Y, Biousse V, Lyden PD (2020) Acute ophthalmic artery occlusion in a COVID-19 patient on apixaban. J Stroke Cerebrovasc Dis 29(8):104982. https://doi. org/10.1016/j.jstrokecerebrovasdis.2020.104982

Efendizade A, Dmytriw AA, Hewitt K, Davies GA (2020) Unfractionated heparin in SARS-CoV-2 Pneumonia: ischemic stroke case report. Front Neurol 11:573356. https://doi.org/10.3389/fneur. 2020.573356

Ehrlich LC, Hu S, Sheng WS, Sutton RL, Rockswold GL, Peterson PK, Chao CC (1998) Cytokine regulation of human microglial cell IL-8 production. J Immunol 160(4):1944-1948

El Nahas N, Roushdy T, Hamid E, Farag S, Shokri H, Fathy M, Aref H (2020) A case series of ischemic stroke with coronavirus disease 2019 in two Egyptian centers. Egypt J Neurol Psychiatr Neurosurg 56(1):120. https://doi.org/10.1186/s41983-020-00259-z

Eliezer M, Hautefort C, Hamel AL, Verillaud B, Herman P, Houdart E, Eloit C (2020) Sudden and complete olfactory loss of function as a possible symptom of COVID-19. JAMA otolaryngology-head $\&$ neck surgery, 146(7)674-675

Elshereye A, Erdinc B (2020) Multiple lacunar cerebral infarcts as the initial presentation of COVID-19. Cureus 12(8):e9638. https:// doi.org/10.7759/cureus.9638

Eskandarani R, Sahli S, Sawan S, Alsaeed A (2021) Simultaneous cardio-cerebral infarction in the coronavirus disease pandemic era: a case series. Medicine (baltimore) 100(4):e24496. https:// doi.org/10.1097/md.0000000000024496

Fayed I, Pivazyan G, Conte AG, Chang J, Mai JC (2020) Intracranial hemorrhage in critically ill patients hospitalized for COVID-19. J Clin Neurosci 81:192-195. https://doi.org/10.1016/j.jocn.2020.08.026

Fifi JT, Mocco J (2020) COVID-19 related stroke in young individuals. The Lancet Neurology 19(9):713-715

Flores G, Kumar JI, Pressman E, Sack J, Alikhani P (2020) Spontaneous brainstem hemorrhagic stroke in the setting of novel coronavirus disease 2019 - a case report. Cureus 12(10):e10809. https:// doi.org/10.7759/cureus.10809

Fu B, Chen Y, Li P (2021) 2019 novel coronavirus disease with secondary ischemic stroke: two case reports. BMC Neurol 21(1):4. https://doi.org/10.1186/s12883-020-02033-3 
Garg A, Marji A, Goyal S, Ismail R (2020) A case of COVID-19 with memory impairment and delayed presentation as stroke. Cureus 12(8):e10025. https://doi.org/10.7759/cureus.10025

Gemcioglu E, Erden A, Davutoglu M, Karabuga B, Kucuksahin O (2020) Acute ischemic stroke in a lupus anticoagulant-positive woman with COVID-19. J Clin Rheumatol 26(6):236-237. https://doi.org/10.1097/rhu.0000000000001565

Ghani MU, Kumar M, Ghani U, Sonia F, Abbas SA (2020) Intracranial hemorrhage complicating anticoagulant prophylactic therapy in three hospitalized COVID-19 patients. J Neurovirol 26(4):602-604. https://doi.org/10.1007/s13365-020-00869-6

Goette A, Patscheke M, Henschke F, Hammwöhner M (2020) COVID-19-induced cytokine release syndrome associated with pulmonary vein thromboses, atrial cardiomyopathy, and arterial intima inflammation. TH Open 4(3):e271-e279. https:// doi.org/10.1055/s-0040-1716717

Goldberg MF, Goldberg MF, Cerejo R, Tayal AH (2020) Cerebrovascular disease in COVID-19. AJNR Am J Neuroradiol 41(7):1170-1172. https://doi.org/10.3174/ajnr.A6588

González RG, Hirsch JA, Koroshetz W, Lev MH, Schaefer PW (2011) Acute ischemic stroke: Springer

Grau AJ, Urbanek C, Palm F (2010) Common infections and the risk of stroke. Nat Rev Neurol 6(12):681-694

Guendouz C, Quenardelle V, Riou-Comte N, Welfringer P, Wolff V, Zuily S, Richard S (2021) Pathogeny of cerebral venous thrombosis in SARS-Cov-2 infection: case reports. Medicine (baltimore) 100(10):e24708. https://doi.org/10.1097/md. 0000000000024708

Guillan M, Villacieros-Alvarez J, Bellido S, Perez-Jorge Peremarch C, Suarez-Vega VM, Aragones-Garcia M, Fernandez-Ferro J (2020) Unusual simultaneous cerebral infarcts in multiple arterial territories in a COVID-19 patient. Thromb Res 193:107109. https://doi.org/10.1016/j.thromres.2020.06.015

Haider A, Schmitt C, Greim CA (2020) Multiorgan point-of-care ultrasound in a patient with coronavirus disease 2019 pneumonia complicated by subarachnoid hemorrhage and pulmonary embolism. A A Pract 14(14):e01357. https://doi.org/10.1213/ xaa.0000000000001357

Halaji M, Farahani A, Ranjbar R, Heiat M, Dehkordi FS (2020) Emerging coronaviruses: first SARS, second MERS and third SARS-CoV-2: epidemiological updates of COVID-19. Infez Med 28(suppl 1):6-17

Han H, Ma Q, Li C, Liu R, Zhao L, Wang W, Liu F (2020) Profiling serum cytokines in COVID-19 patients reveals IL-6 and IL-10 are disease severity predictors. Emerging Microbes \& Infections 9(1): 1123-1130

Haroon KH, Muhammad A, Hussain S, Patro SN (2020) COVID-19 related cerebrovascular thromboembolic complications in three young patients. Case Rep Neurol 12(3):321-328. https://doi. org/10.1159/000511179

Hassett CE, Frontera JA (2021) Neurologic aspects of coronavirus disease of 2019 infection. Current opinion in infectious diseases

Heiat M, Heiat F, Halaji M, Ranjbar R, Yaali-Jahromi E, Azizi M, Badri T (2021) Phobia and fear of COVID-19: origins, complications and management, a narrative review. Ann Ig 33(4):360-370

Heman-Ackah SM, Su YS, Spadola M, Petrov D, Chen HI, Schuster J, Lucas T (2020) Neurologically devastating intraparenchymal hemorrhage in COVID-19 patients on extracorporeal membrane oxygenation: a case series. Neurosurgery 87(2):E147-e151. https://doi.org/10.1093/neuros/nyaa198

Hosseini MJ, Halaji M, Nejad JH, Ranjbar R (2021) Central nervous system vasculopathy associated with severe acute respiratory syndrome coronavirus 2 (SARS-CoV-2): a novel case report from Iran. J Neurovirol 1-3

Iqbal P, Laswi B, Jamshaid MB, Shahzad A, Chaudhry HS, Khan D, Yousaf Z (2021) The role of anticoagulation in post-COVID-19 concomitant stroke, myocardial infarction, and left ventricular thrombus: a case report. Am J Case Rep 22:e928852. https://doi. org/10.12659/ajcr.928852

Kaur I, Vyas C, Mughal M, Gandhi H, Du D (2021) Cerebral venous sinus thrombosis in COVID-19: an unusual presentation. Cureus 13(3):e13767. https://doi.org/10.7759/cureus.13767

Khazaei M, Karimi K, Sedighi P, Khazaei S (2021) Cerebral sinus thrombosis secondary to SARS-CoV-2 infection. Case Rep Neurol Med 2021:6640368. https://doi.org/10.1155/2021/6640368

Kirschenbaum D, Imbach LL, Rushing EJ, Frauenknecht KB, Gascho D, Ineichen BV, Reimann RR (2020) Intracerebral endotheliitis and microbleeds are neuropathological features of COVID- 19 . Neuropathol Appl Neurobiol

Klopfenstein T, Kadiane-Oussou N, Toko L, Royer P-Y, Lepiller Q, Gendrin V, Zayet S (2020) Features of anosmia in COVID-19. Med Mal Infect 50(5):436-439

Krzystanek E, Gawryluk J, Arkuszewski M (2021) Fatal intracranial haemorrhage in a hypertensive patient with atrial fibrillation and coronavirus disease 2019. Neuroradiol J 34(2):147-150. https:// doi.org/10.1177/1971400920978438

Kumar A, Pareek V, Prasoon P, Faiq MA, Kumar P, Kumari C, Narayan RK (2020) Possible routes of SARS-CoV-2 invasion in brain: In context of neurological symptoms in COVID-19 patients. $\mathbf{J}$ Neurosci Res 98(12):2376-2383

Kwon DH, Do Y, Eun MY, Lee J, Park H, Sohn SI, Hong JH (2020) Characteristics of acute stroke in patients with coronavirus disease 2019 and challenges in stroke management during an epidemic. J Korean Med Sci 35(35):e324. https://doi.org/10.3346/jkms.2020.35.e324

Lan J, Ge J, Yu J, Shan S, Zhou H, Fan S, Zhang L (2020) Structure of the SARS-CoV-2 spike receptor-binding domain bound to the ACE2 receptor. Nature 581(7807):215-220

Li G, Fan Y, Lai Y, Han T, Li Z, Zhou P, Liu X (2020a) Coronavirus infections and immune responses. J Med Virol 92(4):424-432

Li Y, Li M, Wang M, Zhou Y, Chang J, Xian Y, Hu B (2020b) Acute cerebrovascular disease following COVID-19: a single center, retrospective, observational study. Stroke Vasc Neurol 5:279284. https://doi.org/10.1136/svn-2020-000431

Liberati A, Altman DG, Tetzlaff J, Mulrow C, Gøtzsche PC, Ioannidis JP, Moher D (2009) The PRISMA statement for reporting systematic reviews and meta-analyses of studies that evaluate health care interventions: explanation and elaboration. J Clin Epidemiol 62(10):e1-e34

Mahboob S, Boppana SH, Rose NB, Beutler BD, Tabaac BJ (2020) Large vessel stroke and COVID-19: case report and literature review. eNeurologicalSci, 20, 100250. https://doi.org/10.1016/j. ensci.2020.100250

Mandel M, Harari G, Gurevich M, Achiron A (2020) Cytokine prediction of mortality in COVID19 patients. Cytokine,134, 155190

Mansour OY, Malik AM, Linfante I (2020) Mechanical thrombectomy of COVID-19 positive acute ischemic stroke patient: a case report and call for preparedness. BMC Neurol 20(1):358. https://doi.org/10.1186/s12883-020-01930-x

Mao L, Jin H, Wang M, Hu Y, Chen S, He Q, Wang D (2020) Neurologic manifestations of hospitalized patients with coronavirus disease 2019 in Wuhan. China JAMA Neurology 77(6):683-690

Mehta P, McAuley DF, Brown M, Sanchez E, Tattersall RS, Manson JJ (2020) COVID-19: consider cytokine storm syndromes and immunosuppression. The Lancet 395(10229):1033-1034

Meng X, Deng Y, Dai Z, Meng Z (2020) COVID-19 and anosmia: a review based on up-to-date knowledge. Am J Otolaryngol 102581

Mirzaee SMM, Gonçalves FG, Mohammadifard M, Tavakoli SM, Vossough A (2020) Focal cerebral arteriopathy in a pediatric patient with COVID-19. Radiology 297(2):E274-e275. https:// doi.org/10.1148/radiol.2020202197 
Mirzaei R, Karampoor S, Sholeh M, Moradi P, Ranjbar R, Ghasemi F (2020) A contemporary review on pathogenesis and immunity of COVID-19 infection. Mol Biol Rep 47(7):5365-5376

Mirzaie A, Halaji M, Dehkordi FS, Ranjbar R, Noorbazargan H (2020) A narrative literature review on traditional medicine options for treatment of corona virus disease 2019 (COVID-19). Complement Ther Clin Pract 101214

Mizuguchi M, Yamanouchi H, Ichiyama T, Shiomi M (2007) Acute encephalopathy associated with influenza and other viral infections. Acta Neurol Scand 115:45-56

Mohammadpour S, Torshizi Esfahani A, Halaji M, Lak M, Ranjbar $\mathrm{R}$ (2021) An updated review of the association of host genetic factors with susceptibility and resistance to COVID-19. J Cell Physiol 236(1):49-54

Morassi M, Bagatto D, Cobelli M, D’Agostini S, Gigli GL, Bnà C, Vogrig A (2020) Stroke in patients with SARS-CoV-2 infection: case series. J Neurol 267(8):2185-2192. https://doi.org/10.1007/ s00415-020-09885-2

Motoie R, Akai M, Kitahara T, Imamura H, Tanabe T, Sarazawa K, Komatsu K (2020) Coronavirus disease 2019 complicated by multiple simultaneous intracerebral hemorrhages. Intern Med 59(20):2597-2600. https://doi.org/10.2169/internalmedicine. $5697-20$

Mousa-Ibrahim F, Berg S, Od TO, Teitcher M, Ruland S (2021) Intracranial hemorrhage in hospitalized SARS-CoV-2 patients: a case series. J Stroke Cerebrovasc Dis 30(1):105428. https://doi.org/ 10.1016/j.jstrokecerebrovasdis.2020.105428

Mowla A, Sizdahkhani S, Sharifian-Dorche M, Selvan P, Emanuel BA, Tenser MS, Mack WJ (2020) Unusual pattern of arterial macrothrombosis causing stroke in a young adult recovered from COVID-19. J Stroke Cerebrovasc Dis 29(12):105353. https://doi. org/10.1016/j.jstrokecerebrovasdis.2020.105353

Nwajei F, Anand P, Abdalkader M, Andreu Arasa VC, Aparicio HJ, Behbahani S, Cervantes-Arslanian AM (2020) Cerebral venous sinus thromboses in patients with SARS-CoV-2 infection: three cases and a review of the literature. J Stroke Cerebrovasc Dis 29(12):105412. https://doi.org/10.1016/j.jstrokecerebrovasdis. 2020.105412

Patel HN, Syed A, Lobel JS, Galler R, Georges J, Carmody M, Puumala M (2020a) Cerebellar infarction requiring surgical decompression in patient with COVID 19 pathological analysis and brief review. Interdiscip Neurosurg 22:100850. https://doi. org/10.1016/j.inat.2020.100850

Patel SD, Kollar R, Troy P, Song X, Khaled M, Parra A, Pervez M (2020b) Malignant cerebral ischemia in a COVID-19 infected patient: case review and histopathological findings. J Stroke Cerebrovasc Dis 29(11):105231. https://doi.org/10.1016/j. jstrokecerebrovasdis.2020.105231

Pavillet CE, Selvakumar TA (2020) SARS-CoV-2 on the neural battleground. Nat Rev Immunol 20(9):518-518

Prasad A, Kataria S, Srivastava S, Lakhani DA, Sriwastava S (2021) Multiple embolic stroke on magnetic resonance imaging of the brain in a COVID-19 case with persistent encephalopathy. Clin Imaging 69:285-288. https://doi.org/10.1016/j.clinimag.2020. 09.010

Priftis K, Algeri L, Villella S, Spada MS (2020) COVID-19 presenting with agraphia and conduction aphasia in a patient with lefthemisphere ischemic stroke. Neurol Sci 41(12):3381-3384. https://doi.org/10.1007/s10072-020-04768-w

Qin C, Zhou L, Hu Z, Zhang S, Yang S, Tao Y, Wang W (2020) Dysregulation of immune response in patients with coronavirus 2019 (COVID-19) in Wuhan. China Clinical Infectious Diseases 71(15):762-768

Rajdev K, Lahan S, Klein K, Piquette CA, Thi M (2020) Acute ischemic and hemorrhagic stroke in COVID-19: mounting evidence. Cureus 12(8):e10157. https://doi.org/10.7759/cureus. 10157

Rascón-Ramírez FJ, Carrascosa-Granada ÁM, Vargas-Jiménez AC, Ferrández-Pujante B, Ortuño-Andériz F (2020) Supra and infratentorial massive strokes in previously healthy young patients with SARS-CoV-2. The Role of Neurosurgery Neurocirugia (astur). https://doi.org/10.1016/j.neucir.2020.08.001

Robinson CP, Busl KM (2020) Neurologic manifestations of severe respiratory viral contagions. Critical care explorations 2(4)

Rochfort KD, Collins LE, Murphy RP, Cummins PM (2014) Downregulation of blood-brain barrier phenotype by pro-inflammatory cytokines involves NADPH oxidase-dependent ROS generation: consequences for interendothelial adherens and tight junctions. PloS One 9(7)e101815

Roy D, Song J, Awad N, Zamudio P (2021) Treatment of unexplained coma and hypokinetic-rigid syndrome in a patient with COVID-19. BMJ Case Rep 14(3). https://doi.org/10.1136/ bcr-2020-239781

Savić D, Alsheikh TM, Alhaj AK, Lazovic L, Alsarraf L, Bosnjakovic P, Yousef W (2020) Ruptured cerebral pseudoaneurysm in an adolescent as an early onset of COVID-19 infection: case report. Acta Neurochir (wien) 162(11):2725-2729. https://doi.org/10. 1007/s00701-020-04510-7

Shang J, Wan Y, Luo C, Ye G, Geng Q, Auerbach A, Li F (2020) Cell entry mechanisms of SARS-CoV-2. Proc Natl Acad Sci 117(21):11727-11734

Song E, Zhang C, Israelow B, Lu P, Weizman OE, Liu F, Wang G (2020) Neuroinvasive potential of SARS-CoV-2 revealed in a human brain organoid model. BioRxiv

Sungnak W, Huang N, Bécavin C, Berg M, Queen R, Litvinukova M, Sampaziotis F (2020) SARS-CoV-2 entry factors are highly expressed in nasal epithelial cells together with innate immune genes. Nat Med 26(5):681-687

Thibodeau R, Jafroodifar A, Quraeshi S, Lisi M (2021) SARS-CoV-2 infection leading to ischemic and hemorrhagic brain lesions and acute respiratory distress syndrome. Radiol Case Rep 16(4):753759. https://doi.org/10.1016/j.radcr.2021.01.025

Thu SS, Matin N, Levine SR (2020) Olfactory gyrus intracerebral hemorrhage in a patient with COVID-19 infection. J Clin Neurosci 79:275-276. https://doi.org/10.1016/j.jocn.2020.07.033

Tu TM, Goh C, Tan YK, Leow AS, Pang YZ, Chien J, Koh J (2020) Cerebral venous thrombosis in patients with COVID-19 infection: a case series and systematic review. J Stroke Cerebrovasc Dis 105379

Valderrama EV, Humbert K, Lord A, Frontera J, Yaghi S (2020) Severe acute respiratory syndrome coronavirus 2 infection and ischemic stroke. Stroke 51(7):e124-e127. https://doi.org/10.1161/strokeaha. 120.030153

Varatharaj A, Galea I (2017) The blood-brain barrier in systemic inflammation. Brain Behav Immun 60:1-12

Viguier A, Delamarre L, Duplantier J, Olivot JM, Bonneville F (2020) Acute ischemic stroke complicating common carotid artery thrombosis during a severe COVID-19 infection. J Neuroradiol 47(5):393-394. https://doi.org/10.1016/j.neurad.2020.04.003

Wang L, He W, Yu X, Hu D, Bao M, Liu H, Jiang H (2020) Coronavirus disease 2019 in elderly patients: characteristics and prognostic factors based on 4-week follow-up. J Infect 80(6):639-645

Wong C, Lam C, Wu A, Ip W, Lee N, Chan I, Chung S (2004) Plasma inflammatory cytokines and chemokines in severe acute respiratory syndrome. Clin Exp Immunol 136: 95-103 In

Zahid MJ, Baig A, Galvez-Jimenez N, Martinez N (2020) Hemorrhagic stroke in setting of severe COVID-19 infection requiring Extracorporeal Membrane Oxygenation (ECMO). J Stroke Cerebrovasc Dis 29(9):105016. https://doi.org/10.1016/j. jstrokecerebrovasdis.2020.105016 
Zhai P, Ding Y, Li Y (2020) The impact of COVID-19 on ischemic stroke. Diagn Pathol 15(1):78. https://doi.org/10.1186/ s13000-020-00994-0

Zhang JM, An J (2007) Cytokines, inflammation and pain. Int Anesthesiol Clin 45(2):27

Zhang J, Sadowska GB, Chen X, Park SY, Kim JE, Bodge CA, Besio WG (2015) Anti-IL-6 neutralizing antibody modulates blood-brain barrier function in the ovine fetus. FASEB J 29(5):1739-1753

Zhu X, Liu Q, Du L, Lu L, Jiang S (2013) Receptor-binding domain as a target for developing SARS vaccines. J Thorac Dis 5(Suppl 2):S142
Ziegler CG, Allon SJ, Nyquist SK, Mbano IM, Miao VN, Tzouanas CN, Hauser BM (2020) SARS-CoV-2 receptor ACE2 is an interferon-stimulated gene in human airway epithelial cells and is detected in specific cell subsets across tissues. Cell 181(5)10161035.e1019

Publisher's Note Springer Nature remains neutral with regard to jurisdictional claims in published maps and institutional affiliations. 